\title{
Simulation Research on On-line Multi-parameter Monitoring for Long Distance Three-phase Power Cable
}

\author{
Bo Zhu*, Xinlao Wei, Hongyan Nie \\ China \\ Email address: \\ zhubo1219@163.com (Bo Zhu),weixinlao@163.com (Xinlao Wei) \\ ${ }^{*}$ Corresponding author
}

Key Laboratory of Engineering Dielectrics and Its Application of Ministry of Education, Harbin University of Science and Technology, Harbin,

\section{To cite this article:}

Bo Zhu, Xinlao Wei, Hongyan Nie. Simulation Research on On-line Multi-parameter Monitoring for Long Distance Three-phase Power Cable. Journal of Electrical and Electronic Engineering. Vol. 7, No. 5, 2019, pp. 126-133. doi: 10.11648/j.jeee.20190705.15

Received: October 15, 2019; Accepted: November 14, 2019; Published: November 18, 2019

\begin{abstract}
Long distance three-phase power cable has the characteristics of the metal sheath cross-bonded and voltage drop and ground potential difference at both ends, which brings confusion to on-line insulation monitoring of long distance power cable. One parameter monitoring cable insulation will effect by voltage drop, load current change, frequency fluctuation and other factor. A method based on dielectric loss factor and resistive current to monitor cable insulation simultaneously has been put forward. The method named as a multi-parameter on-line cable insulation monitoring method. The method installs current transformers and voltage transformers on both side of three-phase cable and uses a high precision timing function of the GPS receiving module at both ends of the testing equipment respectively which can receives the pulse per second from the GPS satellite as time reference can realize the signal synchronous sampling. The principle and formula of the method are given. The metal sheath cross-bonded equivalent circuit of long distance three-phase cable is established by using MATLAB software and does dynamic simulation on the method. The results show that the method is not effect on load current, voltage drop and frequency fluctuation. The two parameters increase obviously when the cable operating temperature exceeds $80^{\circ} \mathrm{C}$. The insulation condition of three-phase cable can be judged by the change of dielectric loss factor and resistive current under different insulation fault. The method was proved to be correctness and feasibility in the paper.
\end{abstract}

Keywords: Long Distance Power Cable, Cross-bonded, Resistive Current, Dielectric Loss Factor

\section{Introduction}

The cross-linked polyethylene (XLPE) cable is widely used in the field of power transmission lines and ultra-high voltage transmission, because of its excellent insulation and mechanical and thermal properties $[1,2]$. In order to meet the power demand, the proportion of the high voltage long distance power cable is increasing. As the length of cable increases, the induced voltage on metal sheath of cable in increasing. In order to solve the problem, the metal sheath must be cross-bonded to eliminate or reduce the induced voltage [3-5]. The basic problems of on-line monitoring insulation for long distance power cables are as following: First, the metal sheath of three-phase cables is cross connection. Second, the long distance cables exists voltage drop. Third, the zero potential at the two terminals of long distance cable is different.
At present, the on-line insulation monitoring methods mainly focus on short distance power cable and the methods cannot be applied to the long distance power cable because of the metal sheath cross connection [6]. There are few research achievements on on-line insulation monitoring for long distance power cable. It will cause huge losses when the insulation of long distance cable is damaged. Therefore, it is very importance to ensure the safe operation of power system.

Some researchers have built up the metal sheath cross-linked of three-phase power cable [6-8]. Boji Sheng and et al. [8], proposed an on-line PD detection and localization by installing current sensors at cable joints or terminations. But the PD signal is weak and complex which can easily be interfered by background noise or electromagnetic interference. The PD signal will occurs multiple refraction and reflection when the signal passes through the metal sheath. Marzinotto and et al. in [9], proposed a method to detect 
sheath faults by monitoring sheath-to-ground currents at the ends of cross-bonding sections, it cannot consider the cable insulation. Marina Adel Shokry and et al. [10], proposed a method for the detection and localization of 4 types of defects in cable sheath. Yang Yang and et al. [11], proposed a method to separate the leakage currents in a cross-bonded system with three-port link boxes which measure sheath currents are a combination of the leakage current of each section and imbalanced circulating current. The above methods only consider one cross-bonded unit cable and need many current sensors to measure currents. Bing Pang and et al. [12], proposed an on-line $\tan \delta$ monitoring method, the value of $\tan \delta$ is susceptible to frequency fluctuation and phase shift during measurement. It can be seen from that the on-line insulation monitoring of cable with a single parameter may be affected by many factors, such as frequency fluctuation, voltage drop, temperature, harmonic, ground potential difference, phase change during measurement and so on [10-13]. Those factors make the monitoring parameter accurately. A method is proposed to judge cable insulation condition by monitoring multi-parameter, such as dielectric loss factor $(\tan \delta)$, resistive current, insulation resistance, impedance and so on. The paper takes dielectric loss factor and resistive current as an example to study. The principle and formula of the multi-parameter method are given and the comparative simulation study proves the feasibility and effectiveness under different conditions.

\section{Theoretical Analysis}

The equivalent of single phase power cable under $\mathrm{AC}$ steady condition is shown in Figure 1. Assumes the length of cable is $2 l, x$ is the any point of the cable, take a differential section $d x$, the current of $x$ point is $\dot{I}_{x}$ and the current of $x+d x$ point is $\dot{I}_{x}+d \dot{I}_{x}$, the voltage of $x$ point is $\dot{U}_{x}$ and the voltage of $x+d x$ point is $\dot{U}_{x}+d \dot{U}_{x} . \dot{U}_{1}$ and $\dot{U}_{2}$ are the voltage at both ends of cable, $\dot{I}_{1}$ and $\dot{I}_{2}$ are the current at both ends of cable core. $R_{0}$ is the unit length equivalent resistance of cable core, $L_{0}$ is the unit length equivalent inductance of cable core, and $G_{0}$ is the unit length equivalent conductance of the cable insulation, $C_{0}$ is the unit length equivalent capacitance of cable insulation.

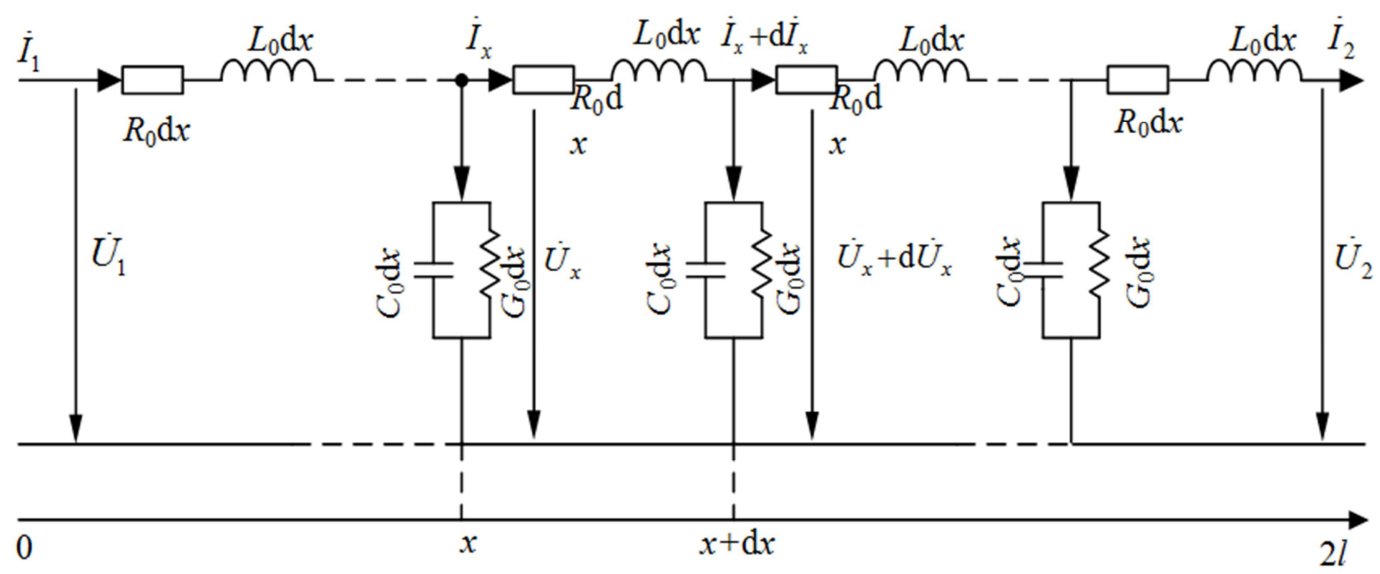

Figure 1. The equivalent of single phase power cable under AC steady condition.

If the voltage and current at head of cable is known, according to the Kirchhoff's Current and Voltage Law for $x$ point [12]:

$$
\left\{\begin{array}{l}
\dot{U}_{x}=\dot{U}_{1} \cosh (\gamma x)-Z_{c} \dot{I}_{1} \sinh (\gamma x) \\
\dot{I}_{x}=\dot{I}_{1} \cosh (\gamma x)-\frac{\dot{U}_{1}}{Z_{c}} \sinh (\gamma x)
\end{array}\right.
$$

Where $\gamma$ is the propagation coefficient, $Z_{c}$ is wave impedance. It can be written:

$$
\left\{\begin{array}{l}
\gamma=\sqrt{Z_{0} Y_{0}}=\sqrt{\left(G_{0}+\mathrm{j} \omega C_{0}\right)\left(R_{0}+\mathrm{j} \omega L_{0}\right)} \\
Z_{c}=\sqrt{\frac{Z_{0}}{Y_{0}}}=\sqrt{\frac{R_{0}+\mathrm{j} \omega L_{0}}{G_{0}+\mathrm{j} \omega C_{0}}}
\end{array}\right.
$$

Similarly, if the current and voltage at the end of the cable are known, it can be obtained:

$$
\left\{\begin{array}{l}
\dot{U}_{x}=\dot{U}_{2} \cosh [\gamma(2 l-x)]+Z_{c} \dot{I}_{2} \sinh [\gamma(2 l-x)] \\
\dot{I}_{x}=\dot{I}_{2} \cosh [\gamma(2 l-x)]+\frac{\dot{U}_{2}}{Z_{c}} \sinh [\gamma(2 l-x)]
\end{array}\right.
$$

According to (1), the voltage and current on the end of the cable can be expressed as (4) when $x$ is equal $2 l$ :

$$
\left\{\begin{array}{l}
\dot{U}_{1}=\dot{U}_{2} \cosh (2 \gamma l)+Z_{c} \dot{I}_{2} \sinh (2 \gamma l) \\
\dot{I}_{1}=\dot{I}_{2} \cosh (2 \gamma l)+\frac{\dot{U}_{2}}{Z_{c}} \sinh (2 \gamma l)
\end{array}\right.
$$

The voltage drop between head and end of the cable can be expressed as (5):

$$
\begin{aligned}
\Delta \dot{U}=\dot{U}_{1}-\dot{U}_{2} & =\dot{U}_{2} \cosh (2 \gamma l)+Z_{c} \dot{I}_{2} \sinh (2 \gamma l)-\dot{U}_{2} \\
& =-2 \dot{U}_{2} \sinh ^{2}(\gamma l)+Z_{c} \dot{I}_{2} \sinh (2 \gamma l)
\end{aligned}
$$

According to (3), the voltage and current on the head of the 
cable can be expressed as (6) when $x$ is equal zero:

$$
\left\{\begin{array}{l}
\dot{U}_{2}=\dot{U}_{1} \cosh (2 \gamma l)-Z_{c} \dot{I}_{1} \sinh (2 \gamma l) \\
\dot{I}_{2}=\dot{I}_{1} \cosh (2 \gamma l)-\frac{\dot{U}_{1}}{Z_{c}} \sinh (2 \gamma l)
\end{array}\right.
$$

The voltage drop between head and end of the cable can be expressed as (7):

$$
\begin{gathered}
\Delta \dot{U}=\dot{U}_{1}-\dot{U}_{2}=\dot{U}_{1}-\dot{U}_{1} \cosh (2 \gamma l)-Z_{c} \dot{I}_{1} \sinh (2 \gamma l) \\
=2 \dot{U}_{1} \sinh ^{2}(\gamma l)+Z_{c} \dot{I}_{1} \sinh (2 \gamma l)
\end{gathered}
$$

(5) and (7) are subtracted to obtain:

$$
\frac{\left(\dot{U}_{1}+\dot{U}_{2}\right) / 2}{\dot{I}_{1}-\dot{I}_{2}}=\frac{Z_{c} \sinh (2 \gamma l)}{-4 \sinh ^{2}(\gamma l)}
$$

According to the circuit impedance theorem, (8) is the equivalent impedance of the main insulation of the cable, which is the ratio of half of the voltage phasor sum and the current difference at both ends of the cable. The equivalent impedance of cable main insulation can be written as:

$$
Z=\frac{\dot{U}}{\dot{I}}=\frac{\left(\dot{U}_{1}+\dot{U}_{2}\right) / 2}{\dot{I}_{1}-\dot{I}_{2}}=\frac{U \angle \theta}{I \angle \varphi}
$$

Where $U$ is the amplitude of voltage on the insulation, $\theta$ is the angle of the voltage, $I$ is the amplitude of the leakage current and $\varphi$ is the angle of the leakage current.

According to the definition of impedance, the equivalent resistance and equivalent impedance are as follows:

$$
Z=\frac{1}{1 / R+\mathrm{j} \omega C}
$$

Where $R$ is the equivalent resistance of cable main insulation, $C$ is the equivalent impedance between cable core and metal sheath, $\omega$ is the angular velocity of the system under working. $R$ and $C$ can be expressed as:

$$
\left\{\begin{array}{l}
R=\frac{1}{\operatorname{Re}(\dot{I} / \dot{U})}=\frac{1}{\operatorname{Re}\left(\frac{\dot{I}_{1}-\dot{I}_{2}}{\left(\dot{U}_{1}+\dot{U}_{2}\right) / 2}\right)} \\
C=\frac{\operatorname{Im}(\dot{I} / \dot{U})}{\omega}=\frac{\operatorname{Im}\left(\frac{\dot{I}_{1}-\dot{I}_{2}}{\left(\dot{U}_{1}+\dot{U}_{2}\right) / 2}\right)}{\omega}
\end{array}\right.
$$

The resistive current and capacitive current flowing through the main insulation can be expressed as:

$$
\left\{\begin{array}{l}
\dot{I}_{R}=\frac{\dot{U}}{R}=\frac{\left(\dot{U}_{1}+\dot{U}_{2}\right)}{2} \cdot \operatorname{Re}\left(\frac{\dot{I}_{1}-\dot{I}_{2}}{\left(\dot{U}_{1}+\dot{U}_{2}\right) / 2}\right) \\
\dot{I}_{C}=\omega C \dot{U}=\frac{\left(\dot{U}_{1}+\dot{U}_{2}\right)}{2} \cdot \operatorname{Im}\left(\frac{\dot{I}_{1}-\dot{I}_{2}}{\left(\dot{U}_{1}+\dot{U}_{2}\right) / 2}\right)
\end{array}\right.
$$

Where $\dot{I}_{R}$ is the resistive current and $\dot{I}_{C}$ is the capacitive current. According to the definition of dielectric loss factor, the cable insulation $\tan \delta$ can be written as:

$$
\tan \delta=\tan [90-(\varphi-\theta)]
$$

\section{Simulation Analysis}

The method needs to install CT and PT and GPS modules at both ends of three-phase cables. Do dynamic simulation by using Matlab software and establish the simulation model of metal sheath cross-bonded of three-phase cable based on the method by using the SimPowerSystem toolbox.

\subsection{Simulation on the Method for Long Distance Three-phase Power Cable}

The $110 \mathrm{kV}$ XLPE cable is selected as the research object for analysis, the parameters of $110 \mathrm{kV}$ XLPE are shown in Table 1 . The unit length equivalent resistance of cable core is $3.28 \times 10^{-5} \Omega / \mathrm{m}$, the unit length equivalent inductance of cable core is $2.138 \times 10^{-7} \mathrm{H} / \mathrm{m}$, and the unit length equivalent conductance of the cable insulation is $1.397 \times 10^{-11} \mathrm{~S} / \mathrm{m}$, the unit length equivalent capacitance of cable insulation is $1.971 \times 10^{-10} \mathrm{~F} / \mathrm{m}$. The length of the whole cable is $12 \mathrm{~km}$ which is divided into ten standard metal sheath cross-bonded units. The length of a small parts of a standard metal sheath cross-bonded unit is $400 \mathrm{~m}$.

Table 1. Parameters of $110 \mathrm{kV}$ XLPE Cable.

\begin{tabular}{ll}
\hline Parameter & Value \\
\hline Cross-sectional conductors $\left(\mathrm{mm}^{2}\right)$ & 800 \\
Cable external diameter $(\mathrm{mm})$ & 100 \\
Conductor diameter $(\mathrm{mm})$ & 34 \\
Insulation thickness $(\mathrm{mm})$ & 16 \\
External shield $(\mathrm{mm})$ & 1.0 \\
Inner shield $(\mathrm{mm})$ & 1.2 \\
Sheath thickness $(\mathrm{mm})$ & 4.5 \\
\hline
\end{tabular}

The simulation model of three-phase long distance power cable under metal sheath cross-bonded is shown in Figure 2.

Table 2. The Theoretical and Simulation Value of Dielectric Loss Factor.

\begin{tabular}{llll}
\hline Parameter & Theoretical values (\%) & Simulation values (\%) & Relative error (\%) \\
\hline A & 0.02257 & 0.02259 & 0.09 \\
B & 0.02257 & 0.02259 & 0.09 \\
C & 0.02257 & 0.02259 & 0.09 \\
\hline
\end{tabular}


Table 3. The Theoretical and Simulation Value of $I_{R}$.

\begin{tabular}{llll}
\hline Parameter & Theoretical values $(\mathbf{m A})$ & Simulation values $(\mathbf{m A})$ & Relative error $(\%)$ \\
\hline A & 18.44 & 18.46 & 0.11 \\
B & 18.44 & 18.46 & 0.11 \\
C & 18.44 & 18.46 & 0.11 \\
\hline
\end{tabular}

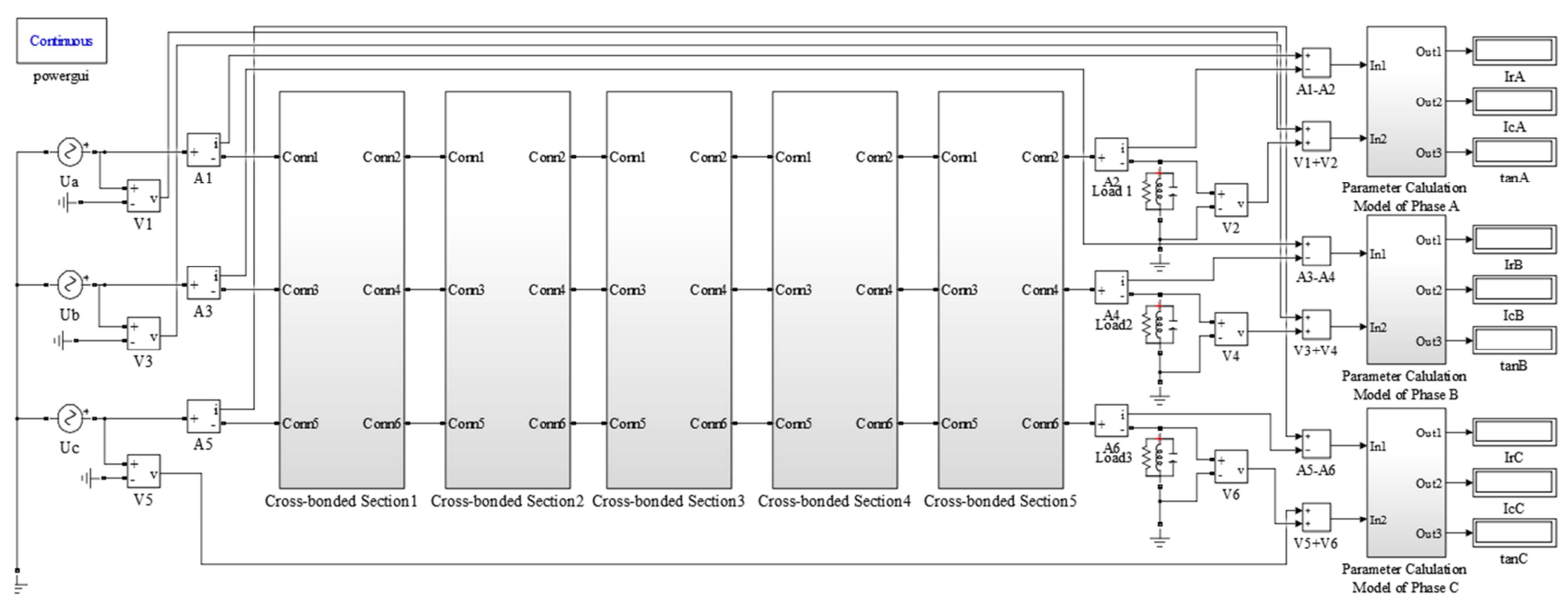

Figure 2. The equivalent of single phase power cable under AC steady condition.

The results are shown that the theoretical values of $\tan \delta$ and $I_{R}$ are basically consistent with the its simulation values, and their relative errors are $0.09 \%$ and $0.11 \%$ respectively. The simulation results prove the correctness of the method.

\subsection{The Voltage at Different Positions Effect on the Method}

The following study the effects of different position voltage on the method. The voltage at two-terminal of cable would influence by the load current, which makes the voltage changing. In order to facilitate analysis, set the load as the resistance load and change the load current by changing the load size. The load resistance value varies from $5 \Omega$ to $600 \Omega$. Such as the phase A, choose the voltage at two-terminal position and half of the voltage phasor sum position to emulate. The simulation results of $\tan \delta$ and $I_{R}$ are shown in Figure 3 and Figure 4 respectively.

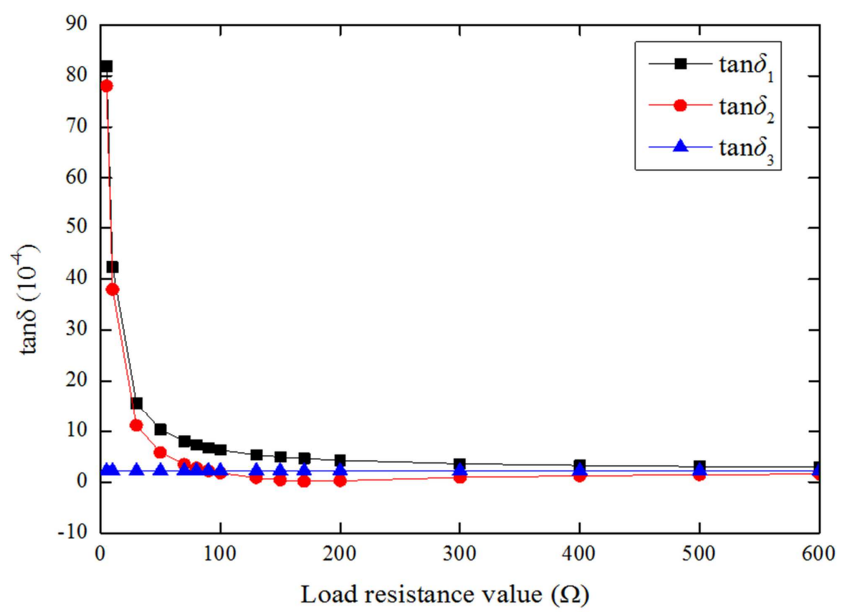

Figure 3. The relation between tan $\delta$ and voltage at different positions of cable.
In the Figure $3, \tan \delta_{1}, \tan \delta_{2}$ and $\tan \delta_{3}$ is respectively calculated which choose head, end and half of the voltage phasor sum positions. The results show that the load current would not effects the $\tan \delta$ calculation which chooses the half of the voltage phasor sum position.

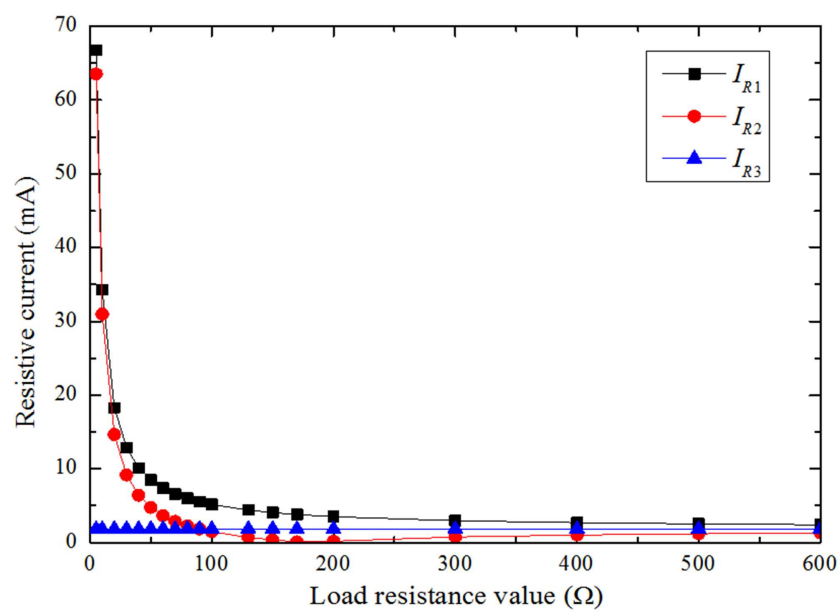

Figure 4. The relation between $I_{R}$ and voltage at different positions of cable.

In the Figure $4, I_{R 1}, I_{R 2}$ and $I_{R 3}$ are respectively calculated which choose head, end and half of the voltage phasor sum positions. The results show that the load current would not effects the $I_{R}$ calculation which chooses the half of the voltage phasor sum position.

\subsection{The Effect of Voltage Drop and Ground Potential Difference at Both Ends of Cable}

The voltage drop is caused by the load current flows through the resistance and inductance of cable core. The following study the effect of voltage drop on the method. Set 
the load is resistance load and the different voltage drop can be obtained by changing the value of the resistance load. The simulation results of $\tan \delta$ and $I_{R}$ are shown in Figure 5.

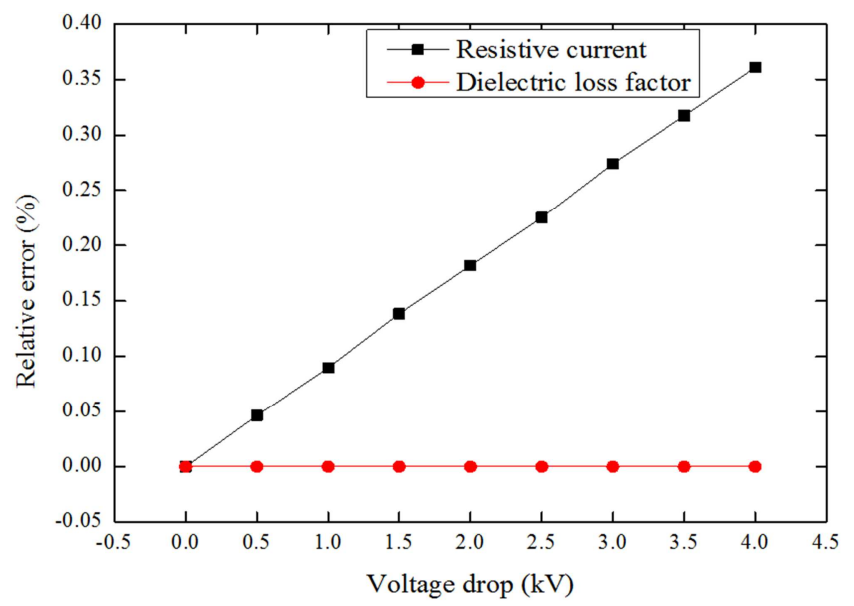

Figure 5. The relation between tan $\delta$ and voltage at different positions of cable.

The results show that the relative error of $I_{R}$ increases with the change of voltage drop, but the relative error is small. And the relative error of $\tan \delta$ is not changed. Therefore, the voltage drop of long distance power cable will has effect on the resistive current and has no effect on $\tan \delta$.

The ground potential at both ends of cable may be different. The following study the effect of ground potential difference on the method. The different ground potential values are simulated in the way which put resistance in series between the load and ground. The simulation results of $\tan \delta$ and $I_{R}$ are shown in Figure 6.

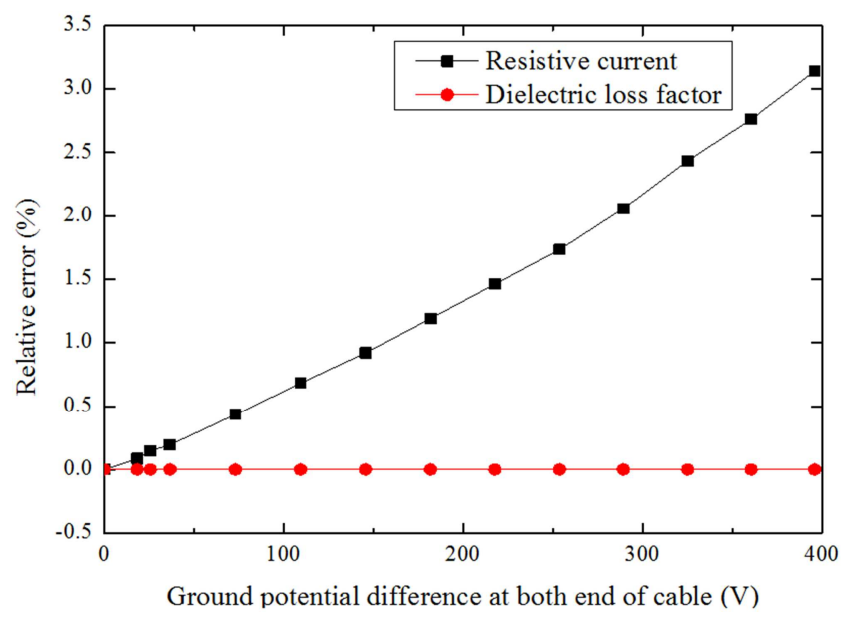

Figure 6. The relative error of $I_{R}$ and tan $\delta$ changes with ground potential difference at both end of cable.

The results show that the relative error of $I_{R}$ increases with the change of ground potential values, but the relative error is small. And the relative error of $\tan \delta$ is not changed. Therefore, the ground potential difference at both ends of long distance power cable will has effect on the $I_{R}$ and has no effect on $\tan \delta$.

\subsection{The Effect of Frequency Fluctuation}

The frequency fluctuation of the power grid leads to barrier effect and frequency leakage caused by asynchronous sampling, which causes errors in monitoring results of cable insulation [17]. Change the frequency of voltage source module from $49.8 \mathrm{~Hz}$ to $50.2 \mathrm{~Hz}$ in Figure 2. The simulation results of $\tan \delta$ and $I_{R}$ change with the frequency fluctuation are shown in Figure 7.



Figure 7. The relative error of $I_{R}$ and tan $\delta$ changes with frequency fluctuation.

The results show that the relative error of $\tan \delta$ changes with the frequency fluctuation, but $I_{R}$ is not changed. Therefore, the frequency fluctuation has effect on $\tan \delta$ and has no effect on $I_{R}$. The simulation of phase change during measurement can get same results that the phase change has effect on $\tan \delta$ and has no effect on $I_{R}$.

\subsection{The Effect of Temperature}

The power cables are usually buried deep underground and the working temperature of XLPE cable is about $80^{\circ} \mathrm{C}$. Once the cable insulation id damaged, the most direct manifestation is temperature rise. It is necessary to study the influence of the temperature on the method. The simulation is accomplished by modifying the insulation resistance of cable at different temperature. The relationship between temperature and conductivity meets Arrhenous-type relation [18].

$$
\sigma(\theta)=\sigma_{0}+A e^{-\frac{B}{\theta+273}}
$$

The parameters of XLPE material used in the paper are set by (16). The initial value of $\sigma_{0}$ is zero, the value of $\mathrm{A}$ is $7.07 \times 10^{-4}$, the value of $\mathrm{B}$ is $8.907 \times 10^{3}, \theta$ is temperature. According to (16), the conductivity at different temperature and the insulation resistance of per $400 \mathrm{~m}$ can be calculated. Set the maximum temperature is $170^{\circ} \mathrm{C}$, because of the melting temperature of XLPE material is $250^{\circ} \mathrm{C}$. Set the minimum temperature is $20^{\circ} \mathrm{C}$. The simulation results of $\tan \delta$ and $I_{R}$ change with the temperature are shown in Figure 8 and Figure 9. 




Figure 8. The relation between $I_{R}$ and temperature.

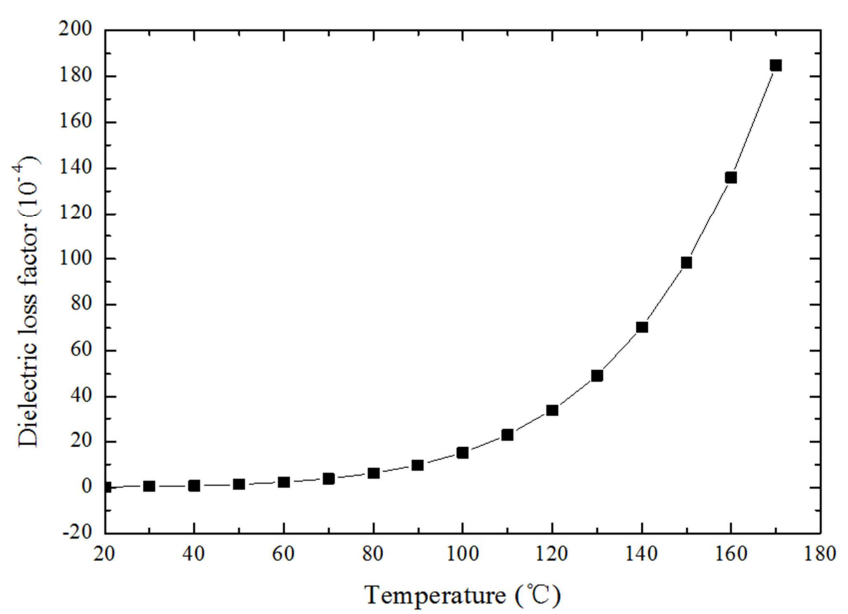

Figure 9. The relation between tan $\delta$ and temperature.

As can be seen from Figure 8 and Figure 9, the relative error of $\tan \delta$ and $I_{R}$ increase exponentially with the temperature is risen.

\subsection{The Effect of Cable Insulation Parameter}

The following study the influence of the variation of the primary parameter of cable insulation on $\tan \delta$ and $I_{R}$ calculation.

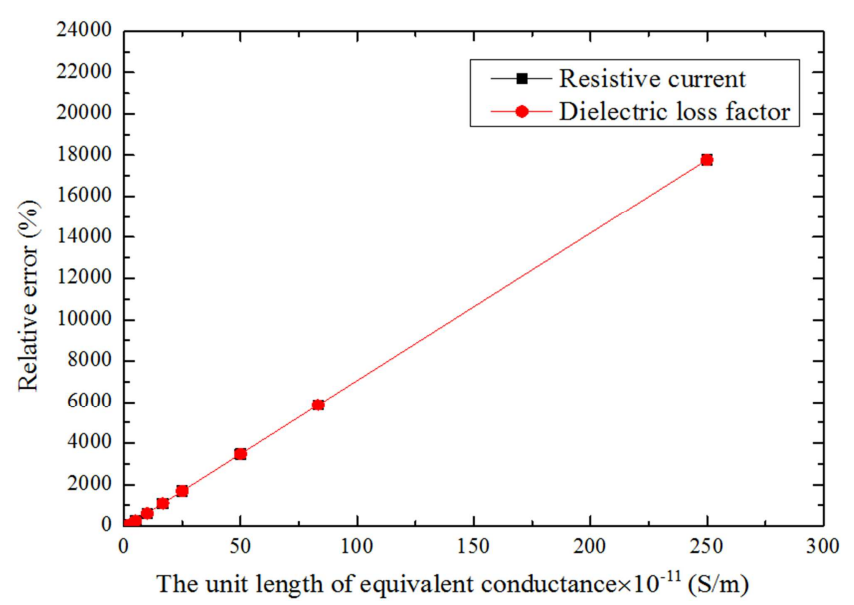

Figure 10. The relation between the unit length of cable insulation equivalent resistance and monitoring parameters.
The variation of cable insulation primary parameter can be achieved by changing the unit length equivalent resistance and capacitance in cable model respectively. The relation between the unit length of equivalent resistance and monitoring parameters is shown in Figure 10. As can be seen from Figure 10, the relative error of $\tan \delta$ and $I_{R}$ are linear increased with increase of the unit length of equivalent conductance.

The relation between the unit length of equivalent capacitance and monitoring parameters is shown in Figure 11 .

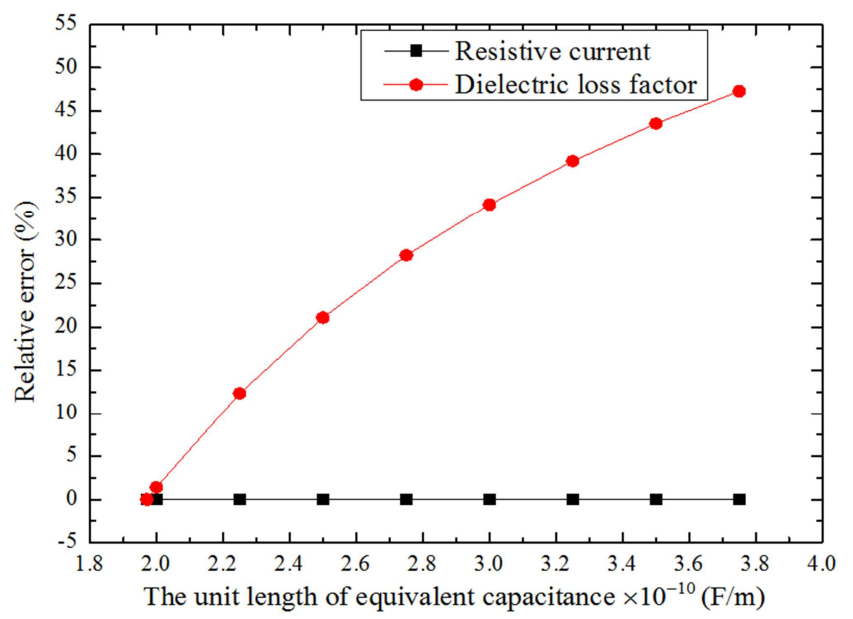

Figure 11. The relation between the unit length of cable insulation equivalent capacitance and monitoring parameters.

As can be seen from Figure 11, the relative error of $\tan \delta$ is exponential increased with increase of the unit length of equivalent conductance, but the value of $I_{R}$ is no changed.

\subsection{Simulation Under Different Fault}

The cable insulation is aging with the cable running longer and the cable insulation resistance will change. Change the value of cable insulation resistance from $180 \mathrm{M} \Omega$ to $1 \mathrm{M} \Omega$ in Figure 2. The results show that $I_{R}$ and $\tan \delta$ are increased obviously with the cable insulation resistance decreases.

The following study the cable under normal, damp, damage and fault insulation state, which would effect on $\tan \delta$ and $I_{R}$. The cable insulation under different faults is simulated by changing the equivalent resistance and capacitance of cable insulation. The parameters of three-phase cable insulation in Figure 2 are set as follows:

(1) Set any one part equivalent resistance of Cross-bonded Section 1 module of A-phase cable is $15 \mathrm{M} \Omega$ and equivalent capacitance is $80 \mathrm{nF}$ to characterize the slight dampness of cable insulation.

(2) Set any part equivalent resistance of Cross-bonded Section 3 module of B-phase cable is $5 \mathrm{M} \Omega$ and equivalent capacitance is $90 \mathrm{nF}$ to characterize the serious dampness of cable insulation.

(3) Set any part equivalent resistance of Cross-bonded Section 5 module of C-phase cable is $0.1 \mathrm{M} \Omega$ and equivalent capacitance is $95 \mathrm{nF}$ to characterize the 
damage of cable insulation.

(4) Set any part equivalent resistance of Cross-bonded Section 2 module of A-phase cable is $0.3 \mathrm{M} \Omega$ and equivalent capacitance is $90 \mathrm{nF}$, set any part equivalent resistance of Cross-bonded Section 4 module of B-phase cable is $0.09 \mathrm{M} \Omega$ and equivalent capacitance is $92 \mathrm{nF}$.

(5) Set any part equivalent resistance of Cross-bonded Section 1 module of A-phase cable is $0.35 \mathrm{M} \Omega$ and equivalent capacitance is $85 \mathrm{nF}$, set any part equivalent resistance of Cross-bonded Section 2 module of B-phase cable is $0.15 \mathrm{M} \Omega$ and equivalent capacitance is $90 \mathrm{nF}$, set any part equivalent resistance of Cross-bonded Section 3 module of C-phase cable is 0.08 $\mathrm{M} \Omega$ and equivalent capacitance is $95 \mathrm{nF}$.

The simulation results under different insulation fault are shown in Table 4.

Table 4. Simulation Results under Different Insulation Fault.

\begin{tabular}{lllllll}
\hline Parameter & Normal & Phase A slightly damp & Phase B serious damp & Phase C insulation damage & A B fault & A B C fault \\
\hline$I_{R \mathrm{~A}}(\mathrm{~A})$ & 0.01846 & 0.08985 & 0.01846 & 0.01846 & 3.61924 \\
$\tan \delta_{\mathrm{A}}(\%)$ & 0.02259 & 0.05138 & 0.02259 & 0.02259 & 0.85467 \\
$I_{R \mathrm{~B}}(\mathrm{~A})$ & 0.01846 & 0.01846 & 0.11903 & 0.01846 & 2.06084 \\
$\tan \delta_{\mathrm{B}}(\%)$ & 0.02259 & 0.02259 & 0.16236 & 0.02259 & 0.28161 \\
$I_{R \mathrm{C}}(\mathrm{A})$ & 0.01846 & 0.01846 & 0.01846 & 2.85402 & 0.37898 \\
$\tan \delta_{\mathrm{C}}(\%)$ & 0.02259 & 0.02259 & 0.02259 & 1.29171 & 3.11583 & 0.01846 \\
\hline
\end{tabular}

The results show that $I_{R}$ and $\tan \delta$ of fault phase increases obviously, which can be judged the cable insulation status. The method to monitor $I_{R}$ and $\tan \delta$ for cable insulation condition is feasible.

\section{Conclusion}

The purpose of the paper is to study on on-line insulation monitoring method for long distance power cable and propose a method to calculate the dielectric loss factor and resistive current by using the core current and voltage at both ends of cable. The results show that:

(1) The load current will not influence on $\tan \delta$ and $I_{R}$ when chooses the half of the voltage phasor sum position. However, chooses other voltage position to calculate $\tan \delta$ and $I_{R}$ which is affected by the load curretn.

(2) The voltage drop and ground potential difference at both ends has little effected on monitoring. The feasibility of the method is demonstrated.

(3) (3) The frequency fluctuation has effect on $\tan \delta$ and has no effect on the resistive current $I_{R}$. The $\tan \delta$ and $I_{R}$ increase obviously when the temperature exceeds $80^{\circ} \mathrm{C}$ and have the same change rate.

(4) The multi-parameter method can be judged the cable insulation status which remedies a single parameter affected by many factors. The method is suitable for all kinds of on-line insulation monitoring of power cable, whether the metal sheath cross-bonded or not.

\section{Acknowledgements}

The work is supported by the National Natural Science Foundation of China (51707048) and University Nursing Program for Young Scholars with Creative Talents in Heilongjiang Province of China (UNPYSCT-2018217). Thanks for all the researchers in Harbin University of Science and Technology.

\section{References}

[1] J. S. Manguelle, M. H. Todorovic, S. Chi, S. Gunturi and R. Datta, "Power transfer capability of HVAC cables for subsea transmission and distribution systems", IEEE Trans. Ind. Appl., vol. 50, no. 4, pp. 2382-2391, Jul./Aug., 2014.

[2] X. Dong, Y. Yang, C. Zhou and D. Hepburn, "Online monitoring and diagnosis of HV cable faults by sheath system currents", IEEE Trans. Power Del., vol. 32, no. 5, pp. 22812290, Oct., 2017.

[3] IEEE Guide for Bonding Metal Sheaths and Shields of Single Conductor Power Cables Rated $5 \mathrm{kV}$ through $500 \mathrm{kV}$, IEEE Standard 575, 2014.

[4] C. F. Jensen, U. S. Gudmundsdottir, C. L. Bak and A. Abur, "Field test and theoretical analysis of electromagnetic pulse propagation velocity on cross-bonded cable systems", IEEE Trans. Power Del., vol. 29, no. 3, pp. 1028-1035, Jun., 2014.

[5] U. S. Gudmundsdottir, B. Gustavsen, C. L. Bak and W. Wiechowski, "Field test and simulation of a $400 \mathrm{kV}$ cross-bonded cable system", IEEE Trans. Power Del., vol. 26, no. 3, pp. 1403-1410, Jan., 2011.

[6] M. Li et al., "A novel fault localization method based on monitoring of sheath current in a cross-bonded HV cable system", in Proc. IEEE Elect. Insul. Conf., Baltimore, MD, USA, 2017, pp. 123-126.

[7] X. Dong, Y. Yuan, Z. Gao, C. Zhou, B. Sheng and H. Zhao, "Analysis of cable failure modes and cable joint failure detection via sheath circulating current", in Proc. IEEE Electr. Insul. Conf., Philadelphia, PA, USA, 2014, pp. 294-298.

[8] B. Sheng, W. Zhou, J. Yu, S. Meng, C. Zhou and D. M. Hepburn, "On-line PD detection and localization in cross-bonded HV cable system", IEEE Trans. Dielectr. Insul., vol. 21, no. 5, pp. 2217-2224, Oct., 2014.

[9] M. Marzinotto and G. Mazzanti, "The feasibility of cable metal sheath fault detection by monitoring metal sheath-to-ground current at the ends of cross-bonding sections", IEEE Trans. Ind. Appl., vol. 51, no. 6, pp. 5376-5384, Nov./Dec., 2015. 
[10] M. A. Shokry, A. Khamlichi, F. Garnacho, J. M. Malo and F. Alvarez, "Detection and localization of defects in cable sheath of cross-bonding configuration by sheath currents", IEEE Trans. Power Del., vol. 34, no. 4, pp. 1401-1411, Aug., 2019.

[11] Y. Yang, D. M. Hepburn, C. Zhou, W. J. Zhou and Y. Bao, "On-line monitoring of relative dielectric losses in cross-bonded cables using sheath currents", IEEE Trans. Dielectr. Electr. Insul., vol. 24, no. 5, pp. 2677-2685, Oct., 2017.

[12] B. Pang, B. Zhu, X. Wei, S. Wang and R. Li, "On-line monitoring method for long distance power cable insulation", IEEE Trans. Dielectr. Electr. Insul., vol. 23, no. 1, pp. 70-76, Feb., 2016.

[13] X. Wei, B. Zhu, B. Pang, S. Wang and R. Li, "On-line monitoring method for long distance power cable insulation", in Proc. IEEE Electr. Insul. Dielectr. Pheno. Conf., Shenzhen, China, 2013, pp. 1081-1084.

[14] F. D. Lenon, M. L. Marquez-Asensio and G. Alvarez-Cordero, "Effects of conductor counter-transposition on the positive-sequence impedance and losses of cross-bonded cables", IEEE Trans. Power Del., vol. 26, no. 3, pp. 2060-2063, July, 2011.

[15] L. Yan, F. Peng, X. Chen, Y. Cheng and X. Li, "Study on metal sheath circulating current of cross-linked power cables", in Proc. Int. Conf. High Voltage Eng. Appl., Chongqing, China, 2008, pp. 645-648.

[16] Y. Yang, D. M. Hepburn, C. Zhou, W. Jiang, B. Yang and W. Zhou, "On-line monitoring and trending of dielectric loss in a cross-bonded HV cable system", in Proc. IEEE 11th Int. Conf. Properties Appl. Dielectr. Mater., Sydney, NSW, Australia, 2015, pp. 301-304.

[17] G. Zhang, J. Liu, S. Zhang, G. Taylor and Y. Liu, "An investigation of frequency fluctuation impact on isolated power system self-excitation", in Proc. IEEE Power Energ. Eng. Conf., Wuhan, China, 2011, pp. 1-15.

[18] G. Teyssedre, C. Laurent, G. C. Montanari, A. Campus and U. $\mathrm{H}$ Nilsson, "From LDPE to XLPE: Investigating the change of electrical properties. Part II . luminescence", IEEE Trans.

[19] Dielectr. Electr. Insul., vol. 12, no. 3, pp. 447-454, June, 2005. 